\title{
Alpha1 Significance
}

National Cancer Institute

\section{Source}

National Cancer Institute. Alpha1 Significance. NCI Thesaurus. Code C67050.

The significance level for the detection p-value in an absolute analysis. 